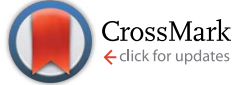

Cite this: Anal. Methods, 2015, 7, 825

Accepted 2nd January 2015

DOI: $10.1039 / c 4 a y 02662 d$

www.rsc.org/methods

\section{A chronopotentiometric flow injection system for aptasensing of E. coli O157†}

\author{
Jiahong Lei, Jiawang Ding* and Wei Qin*
}

In this research, we demonstrate a simple flow injection analysis system for chronopotentiometric aptasensing of E. coli O157. The sensing protocol is based on using an aptamer as a bioreceptor and the current-driven-release of protamine from a polyion-sensitive membrane electrode as a signal reporter.

E. coli 0157 , a notorious pathogen with the production of verocytotoxin, can cause a number of severe diseases that pose a deadly threat to human health. ${ }^{1}$ Therefore, the identification and detection of $E$. coli $O 157$ have received considerable attention, which involve an array of techniques such as cell culture, DNA/ RNA hybridization, ${ }^{2}$ luminescence, ${ }^{3}$ enzyme-linked immunosorbent assays, ${ }^{4}$ polymerase chain reactions, ${ }^{5}$ surface plasmon resonance, ${ }^{6}$ and inductively coupled plasma mass spectrometry. ${ }^{7}$ In recent years, many efforts have been devoted to develop biosensors for the rapid and sensitive detection of bacterial cells. Electrochemical biosensors based on various transduction modes, such as amperometry, potentiometry, and impedimetry, are among the most promising. To date, a number of electrochemical biosensors coupled with a range of biological recognition elements, including antibodies, peptides and aptamers, have been reported for the detection of E. coli O157. ${ }^{8}$

Aptamers are single-stranded DNA or RNA molecules that can bind to a myriad of targets with high affinity that is comparable to an antibody. ${ }^{9}$ Aptasensors utilizing aptamers as bioreceptors have appeared as promising methods for the detection of pathogenic bacteria. Researchers have summarized and evaluated the current applications of electrochemical aptasensors specific for microbial and viral pathogens. ${ }^{10}$ Recently, we developed a label-free potentiometric aptasensor

Key Laboratory of Coastal Environmental Processes and Ecological Remediation, Yantai Institute of Coastal Zone Research (YIC), Chinese Academy of Sciences (CAS), Shandong Provincial Key Laboratory of Coastal Environmental Processes, YICCAS, Yantai, Shandong 264003, P. R. China. E-mail: jwding@yic.ac.cn; wqin@yic.ac.cn; Fax: +86 535 2109000; Tel: +86 5352109156

$\dagger$ Electronic supplementary information (ESI) available. See: DOI: 10.1039/c4ay02662d to monitor bacteria (e.g., Listeria monocytogenes) in a homogeneous solution where the addition of protamine as a signal reporter is involved. ${ }^{11}$ In such sensing protocol, protaminesensitive membrane electrodes are for single-use and cannot monitor the analytes continuously. Flow-injection analysis (FIA) offers high-throughput measurements with rapid and highly reproducible results. ${ }^{12}$ To achieve potentiometric aptasensing with a high sample throughput and low consumption of reagents, FIA can be coupled with the polyion-sensitive membrane electrode. However, to date, no FIA aptasensors for bacteria have been reported. Therefore, potentiometric aptasensors that allow a sensitive and selective detection of $E$. coli O157 in FIA are highly desired.

In recent years, great progress in ion-selective polymeric membrane electrodes has been made by tuning the ionfluxes across the electrode via instrumental control. ${ }^{13}$ Chronopotentiometric sensors, in which ion fluxes are controlled by an applied current, represent an exciting new class of dynamic ion-selective sensors. Bakker et al. explored ion-selective chronopotentiometry to detect alkalinity by imposing an outward flux of hydrogen ions from an ion selective membrane to the sample solution ${ }^{14}$ Recently, polyion-selective pulstrodes have been used as detectors in an FIA measurement configuration for heparin..$^{15}$ In our previous research, we have shown that the indicator ions for potentiometric biosensing could be precisely controlled via current-controlled reagent delivery and could be used for the determination of small analytes and enzymes. ${ }^{16}$ These developed polymeric membrane ion-selective electrodes are reversible and could be utilized as a detector in a FIA system. The FIA systems integrated with those electrodes have been applied successfully to monitor small analytes. In this work, we explore for the first time this avenue by a simple FIA arrangement for chronopotentiometric aptasensing of E. coli O157. It will be shown that $E$. coli $O 157$ can be sensitively and selectively detected via FIA.

Herein, we demonstrate the use of the current-controlledrelease protamine for monitoring bacteria in a FIA system. The sensing mechanism is illustrated in Scheme 1. When an 
anodic current is applied to the electrode, protamine ions are transported across the membrane from the inner solution to the sample, which results in a potential response. The potential response was used as the readout signal. In contrast to conventional ion-selective electrodes, which exhibit Nernstian responses, the present polycation-selective electrode shows the sigmoidal relationship between the potential measured and protamine concentration. In this work, parameters were optimized to ensure the electrode performed in the most sensitive manner. ${ }^{16 c}$ In the absence of the target, ion pairing between the protamine and aptamer is favored due to the strong electrostatical interactions between the aptamer with negatively charged phosphate groups and protamine with positively charged guanidinium groups (Scheme 1A). Protamine ions expelled from the membrane electrostatically interact with the aptamer to form a biocomplex. The consumption of protamine would facilitate the stripping of protamine out of the membrane surface via an ion-exchange process with sodium ions from the sample solution, which can significantly decrease the EMF value. ${ }^{16 c}$ This potential change is correlated to the concentration of aptamer in the solution. When the target bacterium binds to the aptamer, the formation of the biocomplex is disrupted, therefore yielding a potential change, which can be used for the potentiometric detection of E. coli 0157 (Scheme 1B).

As a proof of concept, a polymeric polycation-sensitive membrane electrode was constructed. The membranes contained $3.0 \mathrm{wt} \%$ dinonylnaphthalene sulfonic (DNNS), $6.0 \mathrm{wt} \%$ tetradodecylammonium tetrakis (4-chlorophenyl) borate (ETH 500), $61.0 \mathrm{wt} \%$ 2-nitrophenyl octyl ether (o-NPOE), and $30.0 \mathrm{wt} \%$ poly(vinyl chloride) (PVC) and were prepared as described before. ${ }^{16 a} 0.05 \mathrm{mg} \mathrm{mL}{ }^{-1}$ protamine solution containing $0.12 \mathrm{M}$ $\mathrm{NaCl}$ in $50 \mathrm{mM}$ Tris-HCl buffer ( $\mathrm{pH} 7.4$ ) was used as the inner filling solution. The protamine-conditioned polymeric membrane ion-selective electrode enables the currentcontrolled release of protamine from the inner filling solution to the sample solution. ${ }^{\mathbf{1 1}}$ The protamine released from the

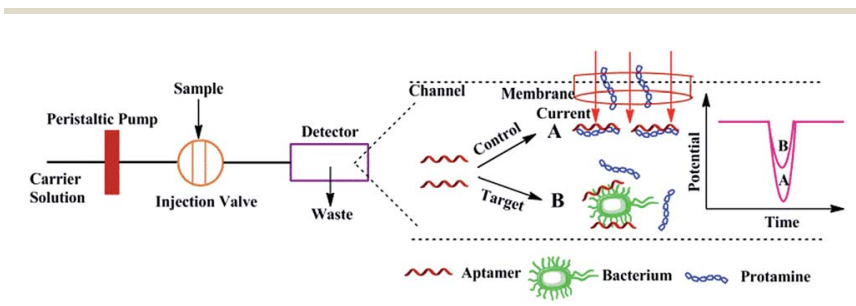

Scheme 1 Schematic illustration of the flow injection chronopotentiometric detection of E. coli $O 157$ using a protamine-sensitive membrane electrode. polyion-sensitive membrane electrode can be utilized as an indicator for potentiometric aptasensing of E. coli O157. The FIA system contains a peristaltic pump, an injection valve and a wall-jet flow cell $(8 \mu \mathrm{L})$ (as shown in Scheme 1$).{ }^{16 d}$ The detection chamber, which was constructed in-house from a single block of Perspex, has a three-electrode system (Fig. S1 in the ESI $\dagger$ ). A high performance liquid chromatography injection valve (Waters E2695, USA) was used for sample injection. A CHI-660C electrochemical workstation (Shanghai Chenhua Apparatus Corporation, China) was used to perform potentiometric measurements using a conventional three-electrode system with a polycationsensitive membrane electrode, a platinum auxiliary electrode, and an $\mathrm{AgCl} / \mathrm{Ag}$ reference electrode. Measurements of electromotive force (EMF) were performed in the cell: $\mathrm{Ag} / \mathrm{AgCl} / 3 \mathrm{M} \mathrm{KCl} /$ sample solution/polymeric membrane/inner filling solution/ AgCl/Ag. A 0.05 M Tris-HCl buffer (pH 7.4) containing $1 \mathrm{mM} \mathrm{NaCl}$ was used as the carrier solution for sample injection and incubation medium for the formation of the bacteria-aptamer complex. The difference in the potential peak height $\left(\Delta E_{\mathrm{h}}\right)$ was used for quantification.

The aptamers for E. coli 0157 were synthesized by Shanghai Sangon Biotechnology Co. Ltd. (Shanghai, China) and their sequences are shown in Table 1. Aptamer solutions were heated at $95{ }^{\circ} \mathrm{C}$ and cooled to room temperature prior to use to obtain the structure flexibilities of the aptamers for binding their targets. ${ }^{17}$

Current pulses or a constant current have been used to control transmembrane ion fluxes of polymeric membrane ionselective electrodes. ${ }^{20}$ In the present work, a constant anodic current was applied across the polymeric membrane polycationsensitive electrode to release protamine from the inner filling solution into the sample solution to obtain a stable baseline. Moreover, the applied current would facilitate the rapid recovery of the membrane electrode. Therefore, the electrode performance is strongly influenced by the applied current. An increase in the applied current can increase the concentration of protamine released at the sample-membrane interface and widen the potential response range, but would decrease the sensitivity for aptamer detection. As a compromise, an anodic current of $10 \mathrm{nA}$ was applied for the controlled release of protamine (Fig. 1A).

The influences of the flow rate and the injected sample volume on the sensitivity of the polycation-sensitive electrode were investigated. As shown in Fig. 1B, with an increase in the flow rate, the potential response is gradually increased, which is probably due to the more efficient electrostatical interactions between the aptamer and protamine in the flow cell induced by

Table 1 Sequences of the aptamers for E. coli 0157

\begin{tabular}{llr}
\hline Aptamer & Sequence & \\
\hline EcO 4 Rev & $5^{\prime}$-ACGGCGCTCCCAACAGGCCTCTCCTTACGGCATATTA-3' & 18 \\
EcO 3 Rev & $5^{\prime}$-GTCTGCGAGCGGGGCGCGGGCCCGGCGGGGGATGCG-3' & 18 \\
E17F-37 & $5^{\prime}$-ATCAAATGTGCAGATATCAAGACGATTTGTACAAGAT-3' & 19 \\
E18R-42 & $5^{\prime}$-CCGGACGCTTATGCCTTGCCATCTACAGAGCAGGTGTGACGG-3' & 19
\end{tabular}



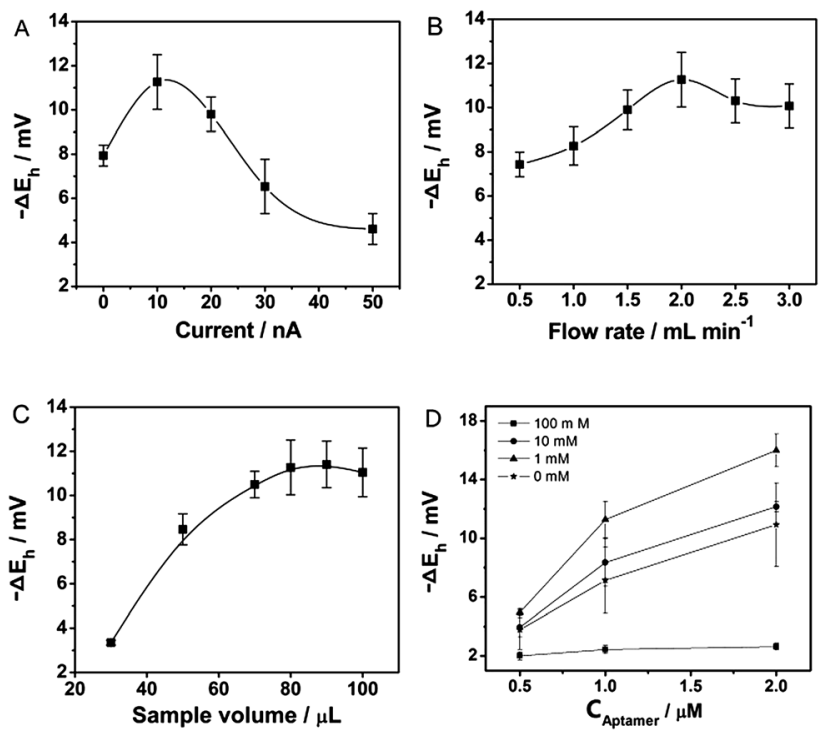

Fig. 1 Effects of (A) current, (B) flow rate, (C) sample volume and (D) buffer concentration on the potential response to the aptamer Eco 3 Rev of $1 \mu \mathrm{M}$ in the FIA system. Unless stated otherwise, the experiments were performed under the following conditions: current, $10 \mathrm{nA}$; flow rate, $2.0 \mathrm{~mL} \mathrm{~min}^{-1}$; sample volume, $80 \mu \mathrm{L}$; buffer solution, $50 \mathrm{mM} \mathrm{pH}$ 7.4 Tris- $\mathrm{HCl}$ buffer containing $1 \mathrm{mM} \mathrm{NaCl}$. Each error bar represents one standard deviation of three measurements.

more vigorous mixing. However, at a flow rate higher than $2.0 \mathrm{~mL} \min ^{-1}$, the electrode response is decreased probably due to a sample dilution effect and/or the short duration for the interaction between the protamine and the aptamer. ${ }^{16 e}$ Fig. $1 \mathrm{C}$ shows that the potential response increases rapidly with increase in the sample volume up to $80 \mu \mathrm{L}$ and then tends to be constant. Therefore, a sample volume of $80 \mu \mathrm{L}$ and flow rate of $2.0 \mathrm{~mL} \mathrm{~min}^{-1}$ were chosen for the present system.

The interfering ions in the buffer solution also have an impact on the potential response due to ion exchange between the interfering ions in the sample solution and protamine in the membrane. Fig. 1D indicates that higher sodium concentrations facilitate the stripping of protamine from the membrane surface and result in a lower potential change. On the other hand, lower sodium concentrations lead to larger noise in potential signal. Therefore, $50 \mathrm{mM} \mathrm{pH} 7.4$ Tris-HCl buffer containing $1 \mathrm{mM} \mathrm{NaCl}$ was used in the subsequent experiments.

Under the optimal experimental conditions, the potentiometric response to the aptamer is shown in Fig. 2. The potential responses decrease in the presence of the aptamer Eco $3 \mathrm{Rev}$ due to electrostatical interaction between the protamine released at the sample-membrane interface and the aptamer in solution. Such decreases will be larger with an increase in aptamer concentration. Moreover, there is a linear relationship between the potential change and the aptamer concentration in the range of $0.1-1.5 \mu \mathrm{M}$. Although higher concentrations of the aptamer cause larger potential changes, it would induce lower sensitivities for the E. coli 0157 detection. Therefore, $1.0 \mu \mathrm{M}$ of the aptamer was employed for the wide response range and high sensitivity.

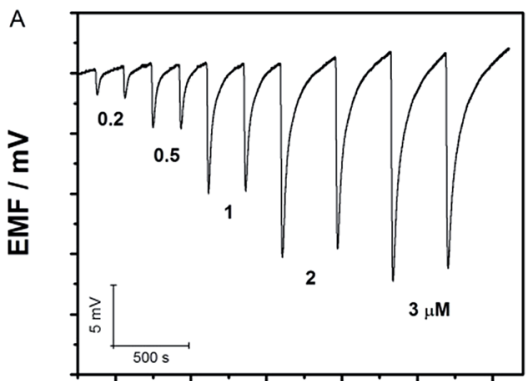

Time / s

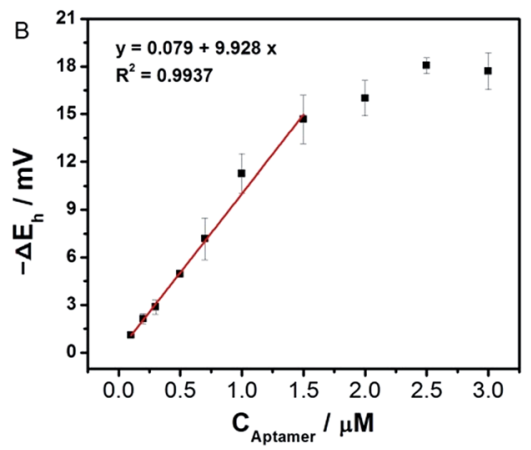

Fig. 2 (A) Potentiometric responses of the electrode to the aptamer Eco 3 Rev. (B) Calibration curve for the aptamer Eco 3 Rev. Each error bar represents one standard deviation of three measurements. The other experimental conditions are as given in Fig. 1.

In recent years, a number of aptamers for E. coli 0157 have been available. ${ }^{18,19}$ In this work, four aptamers with different sequences were compared in terms of their analytical performance. As shown in Fig. 3, all these aptamers can be applied for chronopotentiometric aptasensing of $E$. coli 0157 based on the proposed method. However, a larger potential response can be obtained with the aptamer Eco $3 \mathrm{Rev}$, which may due to the higher affinity of the aptamer to the E. coli O157. Therefore, the aptamer Eco $3 \mathrm{Rev}$ was applied for further experiments.

The E. coli 0157 cells were identified by the chromogenic medium and the concentrations of the bacteria cells were

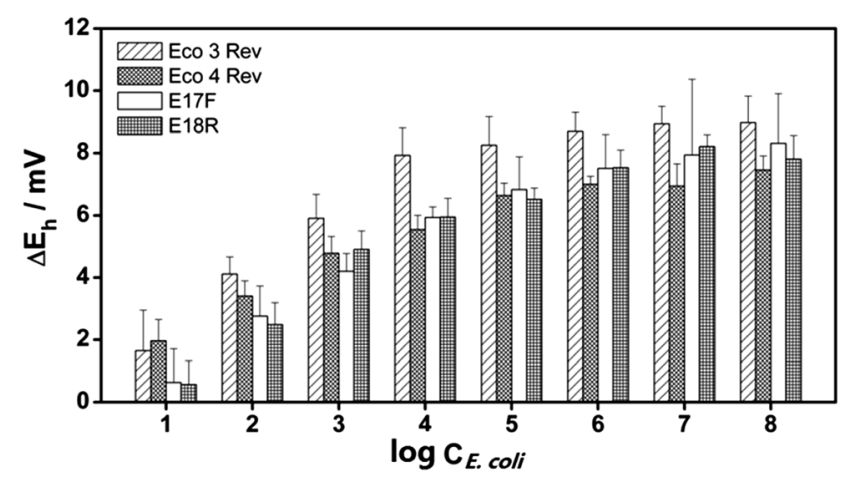

Fig. 3 Determination of E. coli O157 ATCC35150 with $1.0 \mu \mathrm{M}$ of the aptamers Eco 3 Rev, Eco 4 Rev, E17F and E18R. Each error bar represents one standard deviation of three measurements. The other experimental conditions are as given in Fig. 1. 
calculated following the standard plate count method (Fig. S2 and $\mathrm{S} 3$ in the ESI $\dagger$ ). $1.0 \mu \mathrm{M}$ E. coli O157 aptamer was mixed with the target cells at various concentrations in $1.0 \mathrm{~mL}$ Tris buffer. After incubation at room temperature for $1 \mathrm{~h}$, the sample solution was injected into the detection cell. E. coli 0157 at different concentrations induced different decreases in the potential peak height. Under the optimized conditions, the system shows a good linear relationship between the potential response and the cell concentration in the range of $10-10^{4} \mathrm{cfu} \mathrm{mL}^{-1}$. The detection limit was calculated to be $10 \mathrm{cfu} \mathrm{mL}^{-1}(3 \sigma)$ (Fig. S4 in the ESI $\dagger$ ). The detection limit is at least one order of magnitude lower than those obtained by the immunosensors. ${ }^{\mathbf{8}, \boldsymbol{d}, \mathbf{2 1}}$ The comparison between the present chronopotentiometric aptasensing protocol and other detection methods is listed in Table $\mathrm{S} 1 . \dagger$ It should be noted that the aptamer's 3D structure plays a crucial role in its interactions and the buffer environment is very important. ${ }^{22}$ The selection of buffer for the EcO $3 \mathrm{Rev}$ aptamer was originally $0.5 \mathrm{M} \mathrm{NaCl}$, $10 \mathrm{mM}$ Tris, $1 \mathrm{mM} \mathrm{MgCl}_{2} \cdot{ }^{18}$ For the present work, because the interfering ions in the buffer solution have an impact on the potential response due to the ion exchange between the interfering ions in the sample solution and protamine in the membrane, $50 \mathrm{mM}$ pH 7.4 Tris-HCl buffer containing $1 \mathrm{mM}$ $\mathrm{NaCl}$ was used. However, the employed buffer solution has a considerably lower ionic strength and could make the binding toward the E. coli 0157 target considerably weaker, thus leading to the low potential changes observed in Fig. 4.
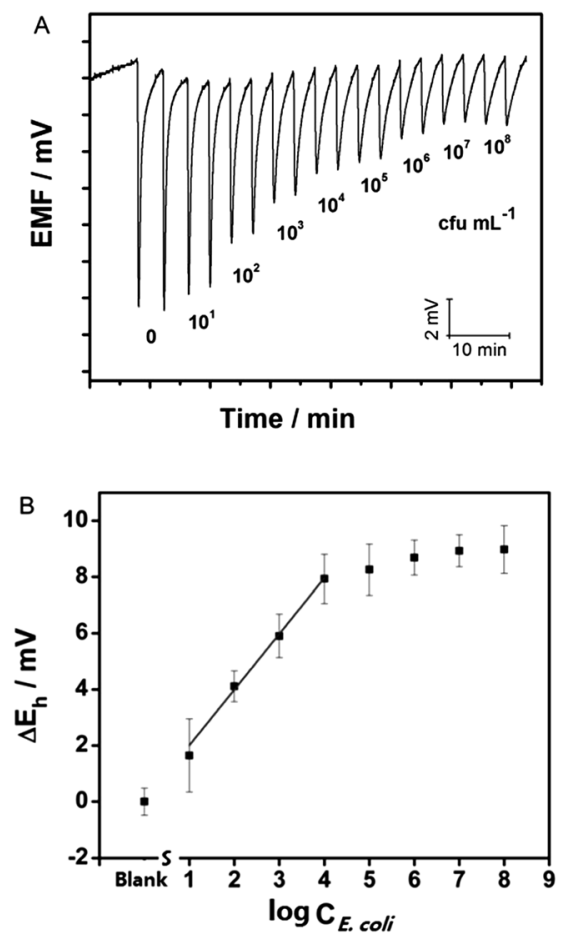

Fig. 4 (A) Potentiometric response of the electrode to E. coli 0157 ATCC 35150 with $1.0 \mu \mathrm{M}$ aptamer Eco $3 \mathrm{Rev}$. (B) Calibration curve for $E$. coli O157. Each error bar represents one standard deviation of three measurements. The other experimental conditions are same as given in Fig. 1.
Further optimization of the membrane composition and other parameters may enhance the sensitivity.

To demonstrate the specificity of the method, the aptasensor was challenged with non-specific bacteria such as Listeria monocytogenes and Salmonella typhimurium. As shown in Fig. S5, $\uparrow$ the proposed sensing system does not respond to high concentrations of nonspecific bacteria but did respond to a low concentration of $E$. coli O157. Our previous research has shown that there is no significant potential change for a scramble DNA sequence in the presence of the target cells, which indicates that the measured potential changes are caused exclusively by the specific interaction between the bacteria and the aptamer. ${ }^{11}$ Similar phenomenon has also been observed in this work (please see Fig. 3 for aptamer selection). Indeed, the DNA segment of E18R shows considerably less response to E. Coli O157 when compared to the aptamer Eco 3 Rev. The good selectivity bodes well for future use of this sensing system in real samples.

\section{Conclusions}

In summary, a flow-injection analysis system for chronopotentiometric aptasensing of $E$. coli 0157 has been demonstrated. The use of a simple current-controlled reagent delivery strategy enables the integration of the polycation-sensitive electrode with flow-injection analysis to achieve a rapid, reproducible and continuous detection of whole cells. The system is readily adaptable to detect other bacteria by changing the aptamers. In addition, coupled to an online filtration system, the FIA system can be used to detect bacteria in real samples.

\section{Acknowledgements}

This work was financially supported by the National Natural Science Foundation of China (41176081, 21207156), the Science and Technology Project of Yantai (2012132) and the Taishan Scholar Program of Shandong Province.

\section{Notes and references}

1 M. Muniesa, J. Jofre, C. Garciä-Aljaro and A. R. Blanch, Environ. Sci. Technol., 2006, 40, 7141-7149.

2 W. C. Liao and J. A. Ho, Anal. Chem., 2009, 81, 2470-2476.

3 S. Ripp, P. Jegier, M. Birmele, C. M. Johnson, K. A. Daumer, J. L. Garland and G. S. Sayler, J. Appl. Microbiol., 2006, 100, 488-499.

4 (a) Y. C. Liu and Y. B. Li, Anal. Chem., 2001, 73, 5180-5183; (b) D. Bavli, N. Emanuel and Y. Barenholz, Anal. Methods, 2014, 6, 395-403.

5 (a) S. C. Donhauser, R. Niessner and M. Seidel, Anal. Chem., 2011, 83, 3153-3160; (b) K. Sen, J. L. Sinclair, L. Boczek and E. W. Rice, Environ. Sci. Technol., 2011, 45, 2250-2256.

6 C. J. Huang, J. Dostalek, A. Sessitsch and W. Knoll, Anal. Chem., 2011, 83, 674-677.

7 F. Li, Q. Zhao, C. Wang, X. F. Lu, X. F. Li and X. C. Le, Anal. Chem., 2010, 82, 3399-3403. 
8 (a) M. R. Akanda, V. Tamilavan, S. Park, K. Jo, M. H. Hyun and H. Yang, Anal. Chem., 2013, 85, 1631-1636; (b) G. A. Zelada-Guillén, S. V. Bhosale, J. Riu and F. X. Rius, Anal. Chem., 2010, 82, 9254-9260; (c) L. J. Yang, Y. B. Li and G. F. Erf, Anal. Chem., 2004, 76, 1107-1113; (d) C. M. Ruan, L. J. Yang and Y. B. Li, Anal. Chem., 2002, 74, 4814-4820; (e) N. V. Kulagina, M. E. Lassman, F. S. Ligler and C. R. Taitt, Anal. Chem., 2005, 77, 6504-6508.

9 A. B. Iliuk, L. H. Hu and W. A. Tao, Anal. Chem., 2011, 83, 4440-4452.

10 M. Labib and M. V. Berezovski, Biosensors based on aptamers and enzymes, Springer-Verlag, Berlin, Germany, 2014, pp. 155-181.

11 J. W. Ding, J. X. Lei, X. Ma, J. Gong and W. Qin, Anal. Chem., 2014, 86, 9412-9416.

12 J. Ruzicka and E. H. Hanse, TrAC, Trends Anal. Chem., 2008, 27, 390-393.

13 (a) E. Bakker, TrAC, Trends Anal. Chem., 2014, 53, 98-105; (b) J. W. Ding, X. W. Wang and W. Qin, ACS Appl. Mater. Interfaces, 2013, 5, 9488-9493.

14 (a) G. A. Crespo, M. G. Afshar and E. Bakker, Anal. Chem., 2012, 84, 10165-10169; (b) M. G. Afshar, G. A. Crespo, X. J. Xie and E. Bakker, Anal. Chem., 2014, 86, 6461-6470.

15 A. K. Bell-Vlasov, J. Zajda, A. Eldourghamy, E. Malinowska and M. E. Meyerhoff, Anal. Chem., 2014, 86, 4041-4046.

16 (a) Y. Chen, J. W. Ding and W. Qin, Bioelectrochemistry, 2012, 88, 144-147; (b) J. W. Ding and W. Qin, J. Am. Chem. Soc.,
2009, 131, 14640-14641; (c) J. W. Ding, Y. Chen, X. W. Wang and W. Qin, Anal. Chem., 2012, 84, 2055-2061; (d) W. J. Song, J. W. Ding, R. N. Liang and W. Qin, Anal. Chim. Acta, 2011, 704, 68-72; (e) J. X. Lei, J. W. Ding and W. Qin, Chem. Bioeng., 2014, 31, 71-765, in Chinese; $(f)$ J. X. Lei, J. W. Ding and W. Qin, Anal. Chim. Acta, 2015, 858, 60-65.

17 Q. Zhao, X. Li, Y. H. Shao and X. C. Le, Anal. Chem., 2008, 80, 7586-7593.

18 J. G. Bruno, M. P. Carrillo, T. Phillips and C. J. Andrews, J. Fluoresc., 2010, 20, 1211-1223.

19 W. H. Wu, J. Zhang, M. Q. Zheng, Y. H. Zhong, J. Yang, Y. H. Hao, W. P. Wu, W. Ye, J. Wen, Q. Wang and J. X. Lu, PLoS One, 2012, 7, e4899.

20 (a) X. U. Zou and P. Bühlmann, Anal. Chem., 2013, 85, 38173821; (b) A. Shvarev and E. Bakker, Anal. Chem., 2003, 75, 4541-4550; (c) E. Lindner, R. E. Gyurcsanyi and R. P. Buck, Electroanalysis, 1999, 11, 695-702.

21 (a) N. Karoonuthaisiri, R. Charlermroj, U. Uawisetwathana, P. Luxananil, K. Kirtikara and O. Gajanandana, Biosens. Bioelectron., 2009, 24, 1641-1648; (b) S. M. Radke and E. C. Alocilja, Biosens. Bioelectron., 2005, 20, 1662-1667.

22 G. Gokulrangan, J. R. Unruh, D. F. Holub, B. Ingram, C. K. Johnson and G. S. Wilson, Anal. Chem., 2005, 77, 1963-1970. 